\title{
Las nuevas fronteras entre documentos escritos y documentos meramente representativos en la era de la documentación informática
}

\author{
The New Borders Between Written Documents and Merely \\ Representative Documents in the Age of Digital Documents \\ Francesco Ricci \\ Full Professor of Private Law at the University LUM «Jean Monnet»of Bari-Casamassima»
}

Sumario: I. Dos conceptos de «documento» en el derecho privado europeo de la moderna sociedad de la información.-II. El documento electrónico en el llamado Reglamento eIDAS (Reglamento (UE) n. ${ }^{\circ}$ 910/2014): el problema de los límites de la forma electrónica como escritura.-III. La relevancia sustancial y probatoria de los documentos sin firma en el derecho italiano vigente.-IV. (sigue) Crítica.-V. Escritos y reproducciones mecánicas.-VI. La valoración ex art. 116 del Codice di procedura civile de los documentos sin firma.-VII. El régimen de los documentos informáticos sin firma y de las reproducciones informáticas.VIII. Los nuevos documentos en derecho de consumo.-IX. El impacto de los nuevos documentos europeos en el Derecho italiano.-X. Conclusiones.

Resumen: A la luz de las nuevas escrituras informáticas de la sociedad de la información y a partir de los dos conceptos diferentes de escritura que se encuentran en la Ley de Interpretación de 1978 del Reino Unido y en el art. 1.11 de los Principios Unidroit, así como de la contraposición del derecho italiano entre «scritture» (escritos) y «riproduzioni meccaniche» (reproducciones mecánicas), el trabajo investiga si la representación o reproducción de palabras en forma visible es necesaria para cumplir con los requisitos del derecho privado europeo en cuanto a la forma y la prueba por escrito, o si es suficiente cualquier forma de comunicación que preserve la documentación de la información contenida y sea reproducible en forma tangible. Argumentando la preferencia por la segunda solución, se establece una distinción entre, por un lado, «documentos declarativos» (es decir, los que constituyen el medio para efectuar declaraciones por escrito) y, por el otro, «documento meramente representativos» (que en cambio no constituyen el medio para efectuar dichas declaraciones), teniendo en cuenta varias normativas vigentes a distinto nivel en el panorama del derecho europeo (y, en particular, ciertas normas del Codice civile, del $B G B$ y del $A B G B$, del Código Civil español, del Código Civil griego y de la Law of Property inglés, por un lado, y el art. 1, 4. ${ }^{\circ}$ apartado, lett. $a$ 
y $c$, de la Convención Unidroit sobre el Factoring internacional y ciertos artículos y Considerandos de la Directiva 85/577/CEE, de la Directiva 97/7/CE y de la Directiva 2011/83/UE, por el otro).

Palabras clave: documento informático; forma y prueba por escrito; firma; firma electrónica y digital; derecho privado europeo

Abstract: Starting from two different concepts of writing, as they can be found in the Interpretation Act of 1978 of United Kingdom and in the article 1.11 of the Unidroit Principles, as well as from the contraposition in Italian law between «scritture» (written documents) and «riproduzioni meccaniche» (mechanical reproductions), the article investigates, in the light of the new issues raised by digital documents in the information society, whether the representation or reproduction of words in a visible form is necessary to comply with the requirements of European private law regarding written form and evidence, or whether any form of communication which preserves the documentation of the information it contains and which is reproducible in a tangible form is sufficient. Arguing the preference for the second solution and taking into account various provisions in force at various levels in the field of European law (and in particular certain provisions of the Codice civile, the BGB, the ABGB, the Código civil, the Greek civil code and the English Law of Property, on the one hand, and of the art. 1(4), letters $a$ and c, of the Unidroit Convention on International Factoring and of certain recitals and articles of Directive 85/577/EEC, of Directive 97/7/ EC and of Directive 2011/83/EU, on the other hand), in the article is drawn a distinction between «written documents», or «declarative documents» (i.e. those which constitute the means of making written declarations), on the one hand, and "purely representative documents» (which do not constitute the means of making such declarations).

Keywords: digital document; written form and evidence; signature; electronic and digital signature; European private Law

\section{Dos conceptos de «documento» en el derecho privado europeo de la moderna sociedad de la información}

Como es sabido, en un procedimiento judicial - como, en realidad, en cualquier ámbito de la vida - el conocimiento de un hecho relevante se puede adquirir de varias formas, y en particular:

i) a través de la percepción directa;

ii) a través de la evidencia crítica o por referencia, es decir, mediante el conocimiento de un hecho diferente pero idóneo para fundar un juicio de tipo inferencial sobre la veracidad del primero con base en la relación objetiva que lo liga a aquel hecho; 
iii) o bien mediante una prueba histórica (prueba documental o prueba testimonial), es decir, mediante la representación de aquel hecho, cuando esta prueba pueda considerarse suficientemente fidedigna, habida cuenta del contexto en el que se realiza o de la credibilidad que se le pueda conceder a su autor.

Entre las representaciones de los hechos se encuentran las narraciones de éstos, es decir, su exposición a través de la utilización de sonidos, signos gráficos u otros símbolos convencionales, portadores de significado. Para plasmar estas narraciones, se utiliza la escritura que, efectivamente, constituye el principal instrumento para una narración no efímera, es decir, que permanece perceptible y, por lo tanto, disponible en el tiempo. No es casualidad que la invención de la escritura marcara el paso de la prehistoria a la historia.

Todos los ordenamientos jurídicos atribuyen una relevancia nuclear a la escritura.

Centrándonos en el panorama europeo del derecho privado, piénsese en la relevancia que se concede a la escritura entendida como la actividad del escribir (en este caso, en la teoría analítica de la declaración se habla de forma o documentación) en los ordenamientos jurídicos que requieren un título como forma contractual ad substantiam (es decir, bajo pena de nulidad) ${ }^{1}$ para la validez de los contratos cuyo objeto es la transmisión de un derecho real inmobiliario (art. 1350 del Codice civile italiano; Law of Property - Miscellaneous Provisions - Act 1989, Section 2) o para el perfeccionamiento del correspondiente efecto traslativo (Law of Property Act 1925, Section 52, que requiere una escritura de propiedad especial llamada «deed»; art. $925 \mathrm{BGB})^{2}$, o incluso para las donaciones, que deben hacerse mediante documento público (art. 518 BGB, art. 943 ABGB, art. 931 del Code civil francés, art. 782 del Codice civile italiano y art. 498 del código civil griego ${ }^{3}$ ). Otro ejemplo lo encontramos en la relevancia atribuida a la forma escrita en los ordenamientos que la prevén como condición de eficacia de las obligaciones contractuales ${ }^{4}$, como es el caso del Derecho español, con respecto a los contratos que tienen por objeto la trasmisión de un derecho inmobiliario (arts. 1279 y 1280 del Código civil).

1 V. para todos Francesco Santoro-Passarelli, Dottrine generali del diritto civile, (Napoli: Jovene, 2016, 9. ${ }^{\mathrm{a}}$ ed.), 144.

${ }^{2}$ Sobre el tema v. Heinz Kötz, European Contract Law (New York, Oxford University Press, 2017, 2. ${ }^{\text {a }}$ ed.), 83 siguientes.

3 Sobre el tema v. Kötz, European ..., 53, así como 75 ss.

${ }^{4}$ V. para todos Luís Díez-Picazo y Antonio Gullón, Sistema de derecho civil, vol. II, t. I, (Madrid: Editorial Tecnos, 2017, 11. a ed.), 40. 
Repárese también en la importancia conferida a la escritura entendida como el resultado del escribir (en este caso, en la teoría analítica de la declaración, se habla de documento), por ejemplo, en España, según se deriva de los arts. 299, n. $^{\circ} 2$ y 3, 317 y siguientes y 324 y siguientes de la Ley 1/2000, de 7 de enero, de Enjuiciamiento Civil, o en Italia según los arts. 2699 y siguientes del Codice civile.

No todos los ordenamientos contienen una definición legal de escritura.

Sin embargo, en primer lugar, puede hallarse una en el Anexo 1 del Interpretation Act $1978^{5}$ que, como es sabido, se aplica en todo el Reino Unido $^{6}$, el cual dispone que: "'writing' includes typing, printing, lithography, photography and other modes of representing or reproducing words in visible form, and expressions referring to writing are construed accordingly».

Para el propósito de este trabajo no importa si aquí por escritura se entiende la acción del escribir (que en la tradición de la teoría analítica de la declaración se denomina actividad de «documentación»), el resultado material (que en la tradición de la teoría analítica se denomina «documento») o las dos cosas. Lo que sí importa es que, en todo caso, de esta noción de escritura se excluye la representación o reproducción de palabras expresadas de forma diferente de la escrita, como es, por ejemplo, el caso de la trasmisión o grabación de palabras pronunciadas por voz. Lo que resulta relevante es que, según esta definición, la escritura es una manera de representar y reproducir palabras de forma visible ${ }^{7}$.

Los Principios Unidroit también ofrecen una noción formal de escritura. De hecho, el primitivo art. 1.10 de los Principios Unidroit de 1994 establecía que «"writing" means any mode of communication that preserves a record of the information contained therein and is capable of being reproduced in tangible form». La misma disposición ahora se encuentra en el art. 1.11 de la edición de 2016 de los Principios Unidroit.

Las dos definiciones no coinciden. De hecho, una cosa es representar o reproducir palabras de forma visible; otra distinta es adoptar una forma de comunicación que conserve la información contenida y sea reproducible de forma tangible.

${ }^{5}$ La norma se puede consultar en el correspondiente sitio web del gobierno, en la dirección web https://www.legislation.gov.uk/ukpga/1978/30/contents; el Anexo I se puede consultar a la dirección web https://www.legislation.gov.uk/ukpga/1978/30/schedule/1.

${ }^{6}$ Para el ámbito de aplicación de dicha norma v. la página web en la dirección https:// www.legislation.gov.uk/ukpga/1978/30/schedule/1?view=extent.

7 Stephen Mason, Electronic Signatures in Law (London: IALS, 2016), http:// humanities-digital-library.org/index.php/hdl/catalog/book/electronicsignatures, ed. Kindle, 1749-1750. 


\section{El documento electrónico en el llamado Reglamento eIDAS (Reglamento (UE) n. ${ }^{\circ}$ 910/2014): el problema de los límites de la forma electrónica como escritura}

Un banco de pruebas para una elección ponderada entre estas definiciones es el ofrecido por el documento informático (o documento electrónico), que anteriormente ya estaba contemplado (pero no regulado ni definido) en la Directiva 1999/93/CE de 13 diciembre de 1999 «por la que se establece un marco comunitario para la firma electrónica» y que, más recientemente, ha sido definido por el Reglamento (UE) n. ${ }^{\circ}$ 910/2014, de 23 julio «relativo a la identificación electrónica y los servicios de confianza para las transacciones electrónicas en el mercado interior y por la que se deroga la Directiva 1999/93/CE» (el llamado «Reglamento eIDAS» ${ }^{8}$ ), según el cual un «documento electrónico» es todo contenido almacenado en formato electrónico, en particular, texto o registro sonoro, visual o audiovisual» (art. 3, n. 35, Reg. eIDAS).

De éstos, sólo el texto entra dentro de la noción de escritura que ofrece el Interpretation Act, mientras que registros sonoros, visuales o audiovisuales no entran dentro de esa noción. Esto se debe a que solo la acción de escribir, y ni siquiera la de hablar, reproduce palabras de manera visible: precisamente en esta diferencia se basa la tradicional contraposición entre la forma escrita y la llamada «oral». Si se considera que esta última expresión puede tomarse de la palabra latina «os», que significa boca, la contraposición entre forma escrita y oral parece evocar el sonido y el sentido del oído como canales de comunicación alternativos a la basada en símbolos y en el sentido de la vista.

En el derecho privado europeo de la moderna sociedad de la información, como primera aproximación, se podría decir que, desde una perspectiva de eficiencia funcional, esta línea fronteriza parece superada. De hecho, el cambio en las prácticas comerciales estimulado por la evolución tecnológica ha determinado definitivamente el tránsito de la contraposición más tradicional entre la noción de «forma escrita» y «forma oral» de las declaraciones (que es la base de la idea de escritura contemplada por la Ley de Interpretación de 1978) a la nueva contraposición, más apropiada para los métodos modernos de comunicación y archivo de la información, entre la noción de «forma documental» y la de «forma efímera» (que es la base de la nueva idea de escritura contemplada por el art. 1.11 Principios Unidroit).

${ }^{8}$ EIDAS es un acrónimo derivado de las iniciales de las palabras en lengua inglesa «electronic IDentification Authentication and Signature». 
Sin embargo, al mirar con más atención, la definición contenida en el Artículo 1.11 de los Principios Unidroit puede conducir a un resultado interpretativo más ambicioso y útil, a saber, el de legitimar la inclusión en el concepto de «escrituras» de todas las declaraciones hechas a través de medios tangibles y duraderos, y no sólo aquellas hechas a través de la documentación de símbolos que debe leer el receptor (y, en esta perspectiva, el de considerar que cuando se hace una declaración de esta forma se respetan las normas que imponen declaraciones o pruebas por escrito, incluso cuando no hay texto con letras visibles a los ojos del destinatario).

La doctrina que se ocupa de ellos no parece ser consciente de esta oportunidad. Por el contrario, a este respecto, incluso se ha comentado que la definición de escritura contenida en el art. 1.11 cit. «is not particularly helpful because it mixes up the formal requirement (a record of information that is capable of being reproduced in tangible form) and the mode of communication that is used to convey the record $»^{9}$. Desde esta perspectiva entonces todas las ventajas de la definición ofrecida por los Principios Unidroit parecen limitarse al hecho de que ella no requiere una caligrafía original, una firma, la firma de un testigo o una firma electrónica certificada y que así, una carta, un fax, un correo electrónico o un SMS se consideran escritos, estén o no firmados y atestiguados ${ }^{10}$.

En cambio, las ventajas derivadas de la definición más moderna de escritura que ofrecen los Principios del UNIDROIT se encuentran precisamente en el hecho de que los registros sonoros, visuales y audiovisuales a que se refiere la definición de documento electrónico que ofrece el Reglamento eIDAS podrían estar legítimamente comprendidos en la definición de escritura que ofrece el art. 1.11 de los Principios Unidroit: esta conclusión se aplica tanto a los requisitos de la forma escrita como a la carga de la prueba por escrito.

En esas condiciones, un documento electrónico puede utilizarse para almacenar en forma duradera tanto las declaraciones hechas en forma escrita (en el sentido más tradicional de ideas representadas por símbolos que el destinatario debe leer), como las declaraciones hechas en forma oral que, por efecto de esta memorización, se recogen de forma duradera y, por lo tanto, son reconducibles a la noción de forma escrita ofrecida por los Principios Unidroit (como en el caso de las grabaciones de audio o de un audiovisual que graba a una persona que habla) y que incluso se pueden firmar electrónicamente, aunque no puedan incluirse en la noción de escritura

${ }^{9}$ Stefan Vogenauer, «Article 1.2 (No form required», en Commentary on the Unidroit Principles of International Commercial Contracts (PICC), editado por Stefan Vogenauer (Oxford: Oxford University Press, 2017, 2a ed.), 159 y siguientes, especialmente 162.

10 Ibidem. 
ofrecida por el Interpretation Act porque no reproducen palabras de forma visible.

Sin embargo, también hay que tener en cuenta que, a pesar de esta extensión del concepto de escritura, no todas las grabaciones de audio o vídeo constituyen una escritura, porque precisamente no son escrituras cuando no son un medio para hacer una declaración, sino sólo una forma ocasional de representarla, pero no afectan en modo alguno a su existencia (como son, por ejemplo, los vídeos grabados como recuerdos familiares, un documental, etc.).

En Europa no sólo falta una literatura jurídica clara y exhaustiva sobre esta distinción, sino también una disciplina analítica que distinga entre las declaraciones hechas por medios tangibles y duraderos y las que simplemente se almacenan en esos documentos, pero que no se hacen a través de ellos.

En cambio, en la legislación italiana existe una interesante regulación de la prueba documental que distingue entre los escritos (entendidos como «documentos declarativos») y los documentos que memorizan y representan hechos sin constituir el medio para hacer declaraciones (y que, por lo tanto, pueden denominarse «documentos meramente representativos»), lo que contribuye a centrar esa distinción. Se trata de un sistema de normas diseñado en los años 30, introducido por el Código Civil italiano de 1942, pero muy actual y aún en vigor, que también incide sistemáticamente en la disciplina de la forma escrita. Merece la pena tenerlo en cuenta porque el enfoque adoptado explícitamente en este sistema de normas ayuda a aclarar de forma resuelta algunas cuestiones concretas y conceptos importantes útiles para la mejor interpretación del Derecho europeo.

El objetivo de este ensayo es mostrar el concepto moderno de escritura y de documento escrito en derecho privado europeo, haciendo referencia no sólo a las definiciones y normas paradigmáticas contenidas en el Reglamento eIDAS y en las Directivas europeas de protección del consumidor, sino también al valioso elemento de reflexión que ofrece el mencionado sistema de normas de Derecho italiano y, en particular, la interesante disposición de este sistema que contempla una categoría particular de documentos llamada «riproduzioni meccaniche» (es decir reproducciones mecánicas) y la contrasta con las escrituras tanto desde el punto de vista conceptual como desde el de su tratamiento jurídico.

Por lo tanto, el derecho italiano no se utilizará como objeto de estudio en sí mismo, sino más bien como una referencia normativa y conceptual que no tiene parangón en otros sistemas jurídicos y que, precisamente por esta razón, ofrece a la comparación jurídica un parámetro que no puede dejar de tener en cuenta quién aspira a comprender y aplicar de forma racional las normas europeas en materia de declaraciones contractuales, las pruebas 
documentales y los requisitos de información que se imponen para proteger a los consumidores, etc.

\section{La relevancia sustancial y probatoria de los documentos sin firma en el derecho italiano vigente}

La ley italiana no ofrece una definición legal de lo que se entiende por documento. Sin embargo, sí establece una distinción que, en abstracto, es análoga a la del Interpretation Act.

De hecho, en el ámbito de la noción unitaria de las pruebas documentales (Libro VI, Titolo II, Capo II), el Codice civile hace una distinción entre los documentos escritos (documento público, documento privado y asientos contables de las empresas sometidas a registro - respectivamente Secciones I, II y III del mencionado Capo, arts. 2699-2711 del Codice civile, en lo sucesivo c.c.-) y las reproducciones mecánicas (Sección IV, art. 2712 c.c.).

Sobre la base de esta distinción:

a) por una parte, la ley italiana dispone que es reproducción mecánica toda «representación mecánica de hechos o cosas» y de esta manera, en principio, parece aludir a las representaciones producidas sobre un soporte material específico por un dispositivo mecánico que reproduce los hechos o las cosas de manera requerida, sin la mediación de la voluntad o de la inteligencia de quien lo acciona, y por esto incluye reproducciones fotográficas, informáticas o cinematográficas y los registros fonográficos (art. 2712 c.c. $)^{11}$;

b) por otra parte, utilizando la expresión «documento redatto» (lo que literalmente significa «documento redactado») $)^{12}$ con rela-

11 Al amparo del art. 2712 cit. «le riproduzioni fotografiche, informatiche o cinematografiche, le registrazioni fonografiche e, in genere, ogni altra rappresentazione meccanica di fatti e di cose formano piena prova dei fatti e delle cose rappresentate, se colui contro il quale sono prodotte non ne disconosce la conformità ai fatti o alle cose medesime». Las reproducciones informáticas se han agregado explícitamente a la lista, la cual no es taxativa, contenida en el art. 2712 c.c., por el art. 23-quater del d.lgs.decreto legislativo de 7 marzo 2005 n. $^{\circ} 82$, así como añadido por el art. 16, apartado 2, del d.lgs.decreto legislativo de 30 diciembre 2010, n. ${ }^{\circ} 235$.

12 De hecho, al amparo del art. 2699 c.c. «l'atto pubblico è il documento redatto, con le richieste formalità, da un notaio o da altro pubblico ufficiale autorizzato ad attribuirgli pubblica fede nel luogo dove l'atto è formato». Esso «fa piena prova, fino a querela di falso, della provenienza del documento dal pubblico ufficiale che lo ha formato, nonché delle dichiarazioni delle parti e degli altri fatti che il pubblico ufficiale attesta avvenuti in sua presenza o da lui compiuti» (art. 2700 c.c.). 
ción al documento público y la palabra «scrittura» (lo que literalmente significa «escritura») en relación con todos los demás documentos distintos del documento público y de las reproducciones mecánicas ${ }^{13}$, parece aludir a los documentos que constituyen el resultado material de la actividad del escribir, es decir, el resultado de la acción de quien dibuja en el papel o en otra superficie adecuada símbolos gráficos que pertenecen a un sistema de escritura y que sirven para representar de manera convencional fenómenos, palabras, ideas, pensamientos, números, de tal manera que quien conozca ese sistema de escritura pueda leerlos e interpretar su sentido.

Se ha afirmado que la ley italiana sienta las bases de una distinción que es análoga a la del Interpretation Act, porque del texto legislativo emerge un dualismo irreconciliable entre el carácter mecánico de las reproducciones contempladas en el art. 2712 c.c. y el carácter consciente y creativo que se asume debe presidir la actividad necesaria para generar un documento escrito:

a) las reproducciones mecánicas, de hecho, se toman en consideración como documento que constituye el resultado de la aplicación a un suporte material de automatismos que dependen directamente de la interacción entre el aparato que genera el documento y una o más características de la realidad que éste retrata (formas, dimensiones, sonidos, luces, colores, peso, movimientos, etc.): son por lo tanto reproducciones mecánicas las fotografías, las grabaciones de audio, los moldes, los trazados de un electrocardiograma, de un sismógrafo, etc.;

b) el documento escrito, en cambio, se toma en consideración como representación gráfica de la voluntad o del pensamiento de su autor (autoridad pública o privada): son por lo tanto documentos los documentos públicos, los documentos privados que contengan una declaración firmada, los papeles y registros domésticos y los asientos contables de las empresas sometidas a registro.

Esto debería llevar a la conclusión de que nunca se puede aplicar la disciplina dedicada a la «representación mecánica de los hechos y de cosas» a un documento escrito, y que, viceversa, a una reproducción de hechos y cosas generada de manera automática por un aparato mecánico tampoco se

13 Dichos documentos incluyen el «documento privado», al que se dedica la Sección II del Capo I cit. (arts. 2702-2708 c.c.), así como las «libros contables de las empresas sujetas a registro», a las que se dedica la Sección III (arts. 2709-2711 c.c.). 
puede aplicar la disciplina dedicada a los documentos escritos (a menos que sea el caso particular de las «copias fotográficas de documentos» específicamente disciplinado por el art. 2718 c.c. ${ }^{14}$ ).

Más precisamente, en aras de una mayor claridad, en este trabajo vamos a prescindir tanto del documento público como de los casos particulares del telegrama, de los documentos y registros domésticos y de los asientos contables de las empresas sometidas a registro, para concentrarnos en general en todos los demás documentos privados.

Con respecto a dichos documentos privados, desde el punto de vista de su relevancia probatoria, con la ley en la mano, las posibilidades se reducen a tres:

i) o son documentos privados firmados, y, por lo tanto, al amparo y por efecto del art. 2702 c.c. constituyen «prueba plena de que el firmante ha hecho las declaraciones representadas por el documento, hasta que se presente una impugnación de falsedad del mismo llamada «querela di falso» (es decir una típica demanda civil para lograr la declaración de falsedad del documento), si la persona frente a quien se pretende que despliegue efectos el documento reconoce su firma, o si ésta se considera como legalmente reconocida»;

ii) o se trata de reproducciones mecánicas, y, por lo tanto, al amparo y por efecto del art. 2712 c.c. «constituyen prueba plena de los hechos y de las cosas representadas, si la persona contra quien se producen no niega su conformidad con los hechos o con las mismas cosas»;

iii) o no se pueden atribuir ni a la primera ni a la segunda de las categorías de pruebas, así que al amparo y por efecto del art. $116 \mathrm{del} C o$ dice di procedura civile italiano, como todas las pruebas que no están sujetas a disciplinas particulares, deben evaluarse según la sana crítica del juez ${ }^{15}$.

En cambio, en el Derecho vigente, se ha ido consolidando la opinión de que los documentos sin firma con los que se manifiesta una voluntad contractual o el conocimiento de cualquier cosa, siendo estructuralmente inadecuado para constituir el medio para efectuar una declaración escrita de voluntad o de ciencia jurídicamente relevante, se deberían

${ }^{14}$ Con base en dicha disposición, «las copias fotográficas de los documentos tienen la misma eficacia de las auténticas, si su conformidad con el original es atestada por una autoridad oficial competente o no se desconoce expresamente».

15 De hecho, el art. 116 c.p.c. dispone que «el juez debe apreciar las pruebas según su prudente arbitrio, a menos que la ley disponga de otro modo». 
equiparar a una declaración oral ${ }^{16}$, mientras, en el plano probatorio, los documentos que los incorporan se deberían considerar como las reproducciones mecánicas que la representan, y por tanto se deberán evaluar al amparo y por efecto del art. 2712 c.c. Se llegó a esta conclusión partiendo de una contraposición entre los simples documentos y las reproducciones mecánicas y, en este marco, sobre la base de la idea más tradicional, pero ahora superada ${ }^{17}$, según la cual a los efectos de una declaración escrita es necesaria la firma de su autor, so pena de inexistencia de la misma ${ }^{18}$,

En estas condiciones, el artículo 2712 c.c. se considera aplicable al caso descrito anteriormente, porque se considera que contiene una cláusula general susceptible de ser aplicada a los documentos producidos por cualquier instrumento mecánico y que, en tales condiciones, sería aplicable a cualquier representación documental que no sean documentos firmados y otros documentos privados especiales, como el telegrama (art. 2705 y siguiente c.c.), los papeles y los registros domésticos (art. 2707 c.c), los asientos contables obligatorios de las empresas (arts. 2709 y siguientes c.c.) ${ }^{19}$.

Sin embargo, este argumento no puede aceptarse.

De hecho, la extensión del art. 2712 c.c. a los documentos no firmados implica una devaluación injustificada, a los efectos de esta disposi-

${ }^{16}$ Salvatore Patti, «Prova documentale», en Commentario del Codice Civile ScialojaBranca, editado por Francesco Galgano, artt. 2699-2720 (Bologna-Roma: Zanichelli, 1996), 132.

17 Sobre el fenómeno dicho de la «crisis de la suscripción» v. Natalino Irti, Studi sul formalismo negoziale (Padova: CEDAM, 1997), 59 y siguientes; Natalino Irti, Idola libertatis (Milano: Giuffrè, 1985), 74 y siguientes. Nos remitimos a lo que se indicó más detalladamente en Francesco Ricci, Scritture private e firme elettroniche (Milano: Giuffrè, 2003), 178 y siguentes.

18 Sobre los documentos firmados, ver la contribución, que en el presente sigue siendo fundamental, de Francesco Carnelutti, «Studi sulla sottoscrizione», Rivista di diritto commerciale (1929): 509 y siguientes; Francesco Carnelutti, Sistema del diritto processuale civile, vol. I (Padova: CEDAM, 1936), 691 y siguientes; así como Giovanni Pavoni, La scrittura privata nel diritto commerciale, Roma, 1914; Vittorio Denti, La verificazione delle prove documentali (Torino: Utet, 1957); Giorgio Laserra, La scrittura privata (Napoli: Jovene, 1959); Mauro Orlandi, La paternità delle scritture - sottoscrizione e firme equivalente (Milano: Giuffrè, 1997). Renviamos nuevamente a Ricci, Scritture private..., cit., 25 y siguientes, 51 y siguientes, 163 y siguientes.

19 Luigi Montesano, «Sul documento informatico come rappresentazione meccanica nella prova civile e nella forma negoziale», Diritto dell'informazione e dell'informatica, n. ${ }^{\circ} 4-5$ (1987): 23 y siguientes, especialmente 26; Patti, «Prova documentale», 126 y 131; Alberto A. Romano, «Il disconoscimento della prova documentale», en Studi in onore di P. Schlesinger, V (Milano: Giuffrè, 2004), 3923 y siguientes, especialmente 3938, así como Luigi Paolo Comoglio, Le prove civili (Torino: Utet Giuridica, 2010, 3. a ed.) 501, nota 66 . 
ción, del carácter mecánico (es decir necesario) de la acción del aparato que imprime los signos representativos sobre el soporte material $\mathrm{y}$, de esta manera, genera el documento. Al mismo tiempo, hace evidente una sobrevaloración de la relevancia de la interposición de un instrumento artificial entre el gesto del autor y la generación del signo imprimido sobre el material, porque en realidad en la perspectiva del art. 2712 c.c. esta circunstancia es relevante solo como elemento que excluye poder considerar el documento como una manifestación subjetiva en forma simbólica de la voluntad o del pensamiento del autor. Basta decir que esta tergiversación, si se aplica con rigor y hasta sus consecuencias extremas, debería llevar a incluir entre las reproducciones mecánicas no solo los signos generados por un aparato complejo de escritura mecánica o electrónica (como era, hace tiempo, la máquina de escribir y como es, ahora, un ordenador), sino también aquellos impresos en el documento simplemente utilizando un lápiz o un bolígrafo.

\section{IV. (sigue) Crítica}

En realidad, la creencia de que, desde el punto de vista sustantivo, el documento carente de firma sería una declaración en forma libre, pero no una prueba escrita, no puede basarse razonablemente en la idea de que la declaración escrita, cuando no está firmada, sería un escrito de autoría incierta y, por lo tanto, que carece de los requisitos necesarios para la forma escrita; en cambio tendría los suficientes para la forma oral, como si esta fuera compatible con dicha incertidumbre.

De hecho, un documento del cual no se pueda conocer su autoría no podría ser atribuido a alguien ni como documento ni como declaración: si, objetivamente, es imposible identificar su autoría, el documento es necesariamente inadecuado para manifestar el estado psicológico interior de una persona y, por lo tanto, es imperfecto en el plano de la forma y completamente deficiente a los efectos de la prueba. En otras palabras, un escrito con estas características sería totalmente incompatible con cualquier forma declarativa, sea escrita u oral, y, por lo tanto, completamente inadecuado para probar cómo se produjo la declaración.

En realidad, los actos del lenguaje son comportamientos simbólicos (que consisten en la composición de signos evocativos escritos, orales o mímicos) destinados a completarse con otros comportamientos de naturaleza diferente (que consisten en la producción de señales que permiten inferir la existencia de realidades más o menos probables, llamadas, precisamente, manifestaciones: entre ellas también la entrega o el envío del documento) y a interpretarse a la luz de las circunstancias, que contribuyen a identifi- 
car las intenciones de su autor ${ }^{20}$ (p.ej., una cosa es manifestar la voluntad de comprar algo en un establecimiento mercantil dedicado a la venta de bienes de aquel tipo, otra es pronunciar la misma frase durante una escena teatral y con un vestuario de teatro).

En estas condiciones, también se pueden obtener elementos útiles para la interpretación de un documento tales como la declaración e inferencias sobre la autoría de aquél a partir de elementos externos a la estructura de aquel documento.

En este contexto, un escrito del que sea posible conocer su autoría aunque sin una prueba preestablecida para este propósito, y en particular sin una firma, puede ser utilizado para dar a conocer el estado interno de voluntad o de ciencia de su autor y, por lo tanto, a nivel sustantivo, es idóneo a los efectos de la declaración, mientras que en el ámbito probatorio, funciona precisamente a la luz de esos elementos (si bien diferentes a una prueba crítica preestablecida) que permiten también en el plano sustancial conocer su autoría, siempre que dichos elementos estén a disposición del receptor.

De estas consideraciones se desprende que un documento escrito no es lo mismo que un documento firmado y que ninguno de los hechos constitutivos de una declaración, de por sí, se ven impedidos por la ausencia de firma del autor de la declaración.

En este sentido, a los efectos de la Convención Unidroit sobre el Factoring internacional ${ }^{21}$ «una comunicación escrita», por un lado, «no necesita ser firmada, pero debe indicar por quién o en nombre de quién se hace»; por el otro «se entiende hecha cuando el destinatario la recibe» (art. 1, apartado 4 , lect. $a$ y $c$ ).

En términos más generales basta pensar en la crisis de los documentos firmados y al empleo extendido de los pedidos enviados por fax en papel con membrete o sello, utilizado por los empresarios en lugar de declaraciones firmadas, incluso antes de la aparición del correo electrónico ${ }^{22}$. O a los muchos escritos a los que, incluso sin la firma del autor, el ordenamiento confiere efectos que, en cambio, se excluyen en la declaraciones orales

${ }^{20}$ Giorgio Giampiccolo, «Dichiarazione recettizia», en Enc. dir. XII (Milano: Giuffrè, 1964), 384 y siguientes; Angelo Falzea, «Manifestazione - teoria generale», en Enc. dir., XXV (Milano: Giuffrè, 1975), 442 y siguientes, especialmente 472; Natalino Irti, Idola libertatis (Milano: Giuffrè 1985), 28; Giuseppe Benedetti, «Parola scritta e parola telematica nella conclusione dei contratti», en Scrittura e diritto, ed. por Aa.Vv. (Milano: Giuffrè, 2000), 75 y siguientes, especialmente 86 .

${ }^{21}$ Unidroit Convention on International Factoring (Ottawa, 26 mayo de 1988), https:// www.unidroit.org/instruments/factoring.

22 Natalino Irti, Studi sul formalismo negoziale (Padova: Cedam, 1997), 59 y siguientes, especialmente 62 . 
(piénsese en las consecuencias de la violación de deberes informativos de origen comunitario que recaen sobre los operadores profesionales, como la ampliación del plazo concedido al consumidor para el ejercicio del derecho de desistimiento, la ineficacia de las condiciones contractuales no comunicadas por escrito o su irrelevancia para la interpretación del contrato $)^{23}$.

Finalmente, incluso en el plano estrictamente probatorio, el Codice civile atribuye eficacia probatoria a documentos no suscritos, como los documentos o registros domésticos o anotaciones.

\section{Escritos y reproducciones mecánicas.}

Hay un elemento que comparten las declaraciones escritas carentes de firma y las firmadas y que las diferencia de las meras reproducciones mecánicas, a saber, el hecho que todas la declaraciones escritas (siendo por definición manifestaciones de voluntad o de ciencia, y no meros actos de lenguaje), independientemente de que estén firmadas, son instrumentos para comunicar a alguien la voluntad del declarante o un dato o hecho conocido por él ${ }^{24}$.

En estas condiciones, todos los documentos (firmados o no) destinados a manifestar la voluntad o la ciencia de alguien (y, a través de ellos, las declaraciones relativas):

a) deben atribuirse a alguien, a quien también deben atribuir la voluntad vinculante (cfr. arts. 1350-1352 c.c.) o el conocimiento de los hechos y de las circunstancias ahí descritos (cfr. arts. 1264, $1 .^{\circ}$ apartado, y 2735 c.c.);

b) tienen un contenido esencialmente simbólico (como tal sujeto a interpretación como instrumento para identificar su significado);

${ }^{23}$ Francesco Ricci, «L'informazione del consumatore e l'inefficacia delle clausole occulte», Temi romana (2000), 829 y siguientes, especialmente 832 y siguientes; Francesco Ricci, «Informazioni per il consumatore e volontarietà del contratto telematico», Temi romana (2000), 841 y siguientes, especialmente 842 y siguientes; Francesco Ricci, «Teleshopping e vendite a distanza nella disciplina delle vendite aggressive», en Materiali e commenti sul nuovo diritto dei contratti, ed. por Giuseppe Vettori (Padova: Cedam, 1999), 258 y siguientes; Ricci, Scritture private..., 178 y siguientes; Francesco Ricci, «Firma digitale», en Diritto civile, ed. por Silvio Martuccelli y Valerio Pescatore (Milano: Giuffrè, 2011), 783 y siguentes, especialmente 784 y 796-797.

${ }^{24}$ Sobre esta diferencia se basa la tradicional distinción entre documentos declarativos y no declarativos (Carnelutti, La prova..., 158 y siguentes), o narrativos (Francesco De Santis, Il documento non scritto come prova civile (Napoli: ESI, 1988), 23, así como 24 y siguientes). 
c) a los efectos de su existencia, se deben enviar a los destinatarios (la llamada emisión de la declaración - véase art. 1328, 2..$^{\circ}$ apartado, c.c.) ${ }^{25}$; d) para alcanzar el resultado práctico deseado por el autor, deben llegar a conocimiento de los destinatarios (cfr. arts. $1326,1334,1335$ c.c.).

En estas condiciones, independientemente de que el autor haya firmado o no el documento, los acontecimientos del documento escrito afectan no solo a la prueba, sino también a la misma existencia del hecho que debe probarse, es decir, la declaración que contribuyen a realizar ${ }^{26}$.

En cambio, no es así en el caso de las reproducciones mecánicas, que no sirven para dar forma a estados mentales (como la existencia de una voluntad vinculante o del estado de conocimiento de ciertos hechos), y que de otra manera quedan relegadas al fuero interno del sujeto. De manera más general, los hechos relativos a estos documentos no afectan a la existencia de los hechos que representan (que pueden probar, pero nunca realizar).

De hecho, a diferencia de los documentos declarativos, las meras reproducciones mecánicas son representaciones de hechos, privadas de sentido propio y provistas de poder evocador, no sujetas a interpretación, sino a inferencia. Además, la mera reproducción mecánica de hechos o cosas no afectan a la existencia del hecho que se quiere probar (que es totalmente independiente con respecto a su representación documental), sino solo a su prueba. Estos documentos no deben (i) ni atribuirse a un autor, (ii) ni emitirse ni ser conocidos por uno o más destinatarios y, al no tener contenido simbólico destinado a la interpretación, no están sujetos a un juicio de genuinidad, entendido como verificación de la correspondencia entre el contenido de la representación y la intención del autor.

Por las razones expuestas, a diferencia de los documentos firmados (regulados desde el punto de vista sustancial por los arts. 1350-1352 c.c., y desde el punto de vista probatorio por los art. 2702 y siguientes c.c.), el ordenamiento jurídico no atribuye la relevancia sustancial propia de la forma de una declaración a la creación de un documento que, en realidad, no se ha formado ni utilizado para declarar algo, sino se limita a disciplinar la sola eficacia probatoria de la reproducción de hechos o cosas allí representados (art. 2712 c.c.).

De estas consideraciones se desprende que las escrituras, aunque carezcan de firma, no tienen la misma naturaleza que las representaciones me-

${ }^{25}$ La noción de declaración, de hecho, designa un hecho interindividual (Pietro Schlesinger, «Dichiarazione (teoria generale)», en Enc. dir. XII (Milano: Giuffrè, 1964), 371 y siguientes, especialmente 376 ).

26 V. más ampliamente Ricci, Scritture private..., 12 y siguientes. 
cánicas de hechos o cosas y que, por lo tanto, también los documentos sin firma deben tratarse como lo que son, es decir, documentos escritos, y no como reproducciones mecánicas.

Lo que, en cambio, distingue a los documentos no firmados de los firmados es que solo en estos últimos, mediante la firma, su autor proporciona al destinatario la prueba crítica del origen del documento ${ }^{27}$.

Cuando esto ocurre, la autoría del documento y de la declaración hecha a través de él se ven favorecidas por la propia estructura del documento, que incluye no solo el contenido de la comunicación y la indicación de su autor, sino también la prueba crítica de su autenticidad, preestablecida por un marco o signo distintivo (tal es, precisamente, la firma ${ }^{28}$ ): tras la verificación del marco, el documento firmado y la relativa declaración se consideran atribuibles al sujeto destinatario ${ }^{29}$, a menos que no se facilite prueba de la falsificación, esto es, una prueba contraria capaz de contradecir la inferencia basada en la rúbrica.

\section{La valoración ex art. 116 del Codice di procedura civile de los documentos sin firma}

De las consideraciones expuestas se puede deducir que, a los efectos de la prueba de la manifestación realizada a través de ellos, los documentos sin firma no se pueden reconducir directamente:

- ni al régimen particular de los documentos firmados al que se refieren el art. 2702 c.c. y los arts. 214 y siguientes del Codice di procedura civile - en lo sucesivo c.p.c. (porque, pese a estar basados en la naturaleza declarativa del documento, éstos se centran en la presencia de pruebas críticas preestablecidas sobre el origen del documento mediante la colocación de la firma del autor);

- ni al régimen legal de las representaciones mecánicas al que se refiere el art. 2712 c.c., si se entiende como una excepción al principio de la libre valoración de la prueba (porque esto consistiría en atribuir

27 En este sentido, cfr. V. Dentr, La verificazione..., 3; S. MASON, Electronic..., 1633 y siguientes, 1683-1684, 1721-1723, 1737-1739; Xavier Abel Lluch, La valoración de la prueba en el proceso civil (Madrid: La Ley, 2014), ed. Kindle, 1033-1035.

28 V. para todos, Francesco Carnelutti, Teoria generale del diritto (Napoli: ESI, 1951, 3. ${ }^{\text {a }}$ ed.), 388; Denti, La verificazione..., 4. Sobre el tema v. ampliamente Ricci, Scritture private..., 51 y siguientes.

29 Más precisamente (cfr. Denti, La verificazione..., 4) se forma la prueba por presunciones de que el documento firmado proviene del sujeto designado. 
una admisibilidad particular a las reproducciones directas de hechos o cosas mediante otras cosas representativas que, a diferencia de los documentos escritos, no constituyen el instrumento para la propia realización de los hechos que representan, sino que simplemente representan esos hechos sin contribuir a su realización).

En tal caso, podría entenderse que los documentos sin firma no deben considerarse sujetos al particular efecto probatorio previsto, como excepción al principio de la libre valoración de la prueba previsto en el art. 116 c.p.c., tanto para los documentos firmados, como (según la referida orientación) para las reproducciones mecánicas (entendida como una norma especial que atribuye a tales pruebas la eficacia de la prueba plena, a salvo de la apreciación del juez como excepción al principio de la libre valoración de la prueba ${ }^{30}$ ) y que, por lo tanto, deben considerarse sujetos al principio establecido en términos generales para todos los casos no previstos específicamente por el art. 116 cit., y, por lo tanto, sujetos al prudente arbitrio del juez, quien queda así desvinculado de los límites que, de otro modo, impondría la calificación de dichos documentos como prueba plena en el sentido de una o, según la interpretación predominante, de la otra disposición.

De hecho, esta parece ser la valoración que hace el «Codice dell'amministrazione digitale» (decreto legislativo d.lgs. 7 marzo de 2005, n. ${ }^{\circ} 82$, en adelante C.a.d.), que, como regla general, cuando se trata de un documento sin firma, deja a la libre valoración del intérprete tanto el juicio sobre la «idoneidad del documento informático para cumplir el requisito de la forma escrita», como sobre su «valor probatorio», entendiéndose que a ambos efectos el intérprete debe tener en cuenta «sus características objetivas de calidad, seguridad, integridad e inmodificabilidad» (art. 20, apartado 1 bis $)^{31}$.

30 Sin embargo, Enrico Tullio Liebman, Manuale del processo civile, vol. II, (Milano: Giuffrè, 1981, 4. ${ }^{\mathrm{a}}$ ed.), 120, a propósito de las reproducciones mecánicas del art. 2712 c.c., indica que «se trata de prueba sujeta al principio general de la libre valoración».

31 En particular, el art. 20, apartado 1-bis prevé que «il documento informatico soddisfa il requisito della forma scritta e ha l'efficacia prevista dall'articolo 2702 del Codice civile quando vi è apposta una firma digitale, altro tipo di firma elettronica qualificata o una firma elettronica avanzata o, comunque, è formato, previa identificazione informatica del suo autore, attraverso un processo avente i requisiti fissati dall'AgID ai sensi dell'articolo 71 con modalità tali da garantire la sicurezza, integrità e immodificabilità del documento e, in maniera manifesta e inequivoca, la sua riconducibilità all'autore. In tutti gli altri casi, l'idoneità del documento informatico a soddisfare il requisito della forma scritta e il suo valore probatorio sono liberamente valutabili in giudizio, in relazione alle caratteristiche di sicurezza, integrità e immodificabilità. La data e l'ora di formazione del documento informatico sono opponibili ai terzi se apposte in conformità alle Linee guida». 
Pero lo que se refiere a los efectos del acto declarativo desde el punto de vista sustancial, la evaluación de la idoneidad del documento para cumplir el requisito de la forma escrita sigue siendo libre, al amparo del art. 20 cit., incluso cuando los documentos informáticos están firmados. Este principio se excluye explícitamente solo a los efectos de la forma de los documentos privados escritos a los que se refiere el art. $1350,1 .^{\circ}$ apartado, números 1-12, c.c., que «si se hacen en documento informático» deben estar «firmados, so pena de nulidad, con una firma electrónica cualificada o firma digital» (art. 21, apartado 2-bis), a menos que la firma esté autentificada por un notario u otro funcionario público autorizado al efecto. En este último caso, se puede adoptar una firma electrónica o cualquier otro tipo de firma avanzada, así como la obtención digital de la firma autógrafa: de hecho, el art. 21, apartado 2-bis, dice «salvo el caso de una suscripción autenticada por un notario u otro funcionario público» contemplado en el artículo 25 C.a.d., en virtud del cual, por un lado, «se reconoce, al amparo del art. 2703 c.c., la firma electrónica o cualquier otro tipo de firma avanzada autentificada por un notario u otro funcionario público autorizado al efecto» (1. ${ }^{\circ}$ apartado c.; cfr. art. 2703, 1. ${ }^{\circ}$ apartado c.c.); y, por otra parte, «la autentificación de la firma electrónica, incluso mediante la obtención digital de la firma autógrafa, o de cualquier otro tipo de firma electrónica avanzada, consiste en la certificación por un funcionario público de que la firma se ha hecho en presencia del titular, previa verificación de su identidad personal, de la validez del eventual certificado electrónico utilizado y del hecho que el documento firmado es contrario al ordenamiento jurídico» (2. ${ }^{\circ}$ apartado; $\mathrm{cfr}$. art. $2703,2 .^{\circ}$ apartado, c.c.).

También el documento informático firmado con firma electrónica, desde el punto de vista probatorio puede ser libremente valorado en juicio, teniendo en cuenta sus características objetivas de seguridad, integridad e inmodificabilidad (art. 20, apartado 2-bis, C.a.d.). Solo si el documento informático se ha firmado con firma electrónica avanzada, cualificada o digital, o «cuando, en todo caso, se constituya, tras la identificación informática de su autor, mediante un procedimiento que cumpla los requisitos establecidos por la AgID [es decir, Agenzia per l'Italia Digitale $^{32}$ ] de conformidad con el artículo 71, de forma que se garantice la seguridad, integridad e inalterabilidad del documento y, de forma clara e

${ }^{32}$ La Agenzia per l'Italia Digitale es la agencia técnica de la Presidencia del Consejo encargada de garantizar la consecución de los objetivos de la Agenda Digital Italiana y de contribuir a la difusión del uso de las tecnologías de la información y de la comunicación, incentivando la innovación y el desarrollo económico. 
inequívoca, su trazabilidad hasta el autor $»^{33}$, podrá tener «la eficacia prevista en el art. 2702 del Codice civile» y, en tal caso, «se presume que el uso del dispositivo de firma es atribuible al titular, salvo que se demuestre lo contrario» (art. 20, apartado 2. ${ }^{\circ}$ bis, C.a.d.).

\section{El régimen de los documentos informáticos sin firma y de las reproducciones informáticas}

Las consideraciones expuestas contribuyen a resolver el problema que ha sido planteado por quienes han puesto de relieve que dos normas del mismo texto normativo no pueden disciplinar de manera distinta el valor probatorio de lo que se considera el mismo caso, es decir el documento informático sin firma, observando que, por una parte, el art. 20, apartado $1 .{ }^{\circ}$ bis, dispone como regla general que el valor probatorio del documento informático se puede valorar libremente en juicio; mientras que, por la otra, el art. 23 quater C.a.d. ha modificado la dicción del art. 2712 c.c., estableciendo que tanto las reproducciones informáticas, como las demás reproducciones mecánicas, constituyen prueba plena de los hechos y de las cosas representadas, si contra quien se producen no niega su conformidad con los hechos o las cosas en sí mismas y al respecto ${ }^{34}$.

En realidad, como se ha expuesto en los apartados anteriores, las dos disposiciones contemplan dos supuestos diferentes y son, por lo tanto, compatibles entre sí: la línea divisoria entre documentos informáticos relevantes según el art. 2712 c.c. y aquellos relevantes a los efectos de la exigencia de la forma y la prueba de las manifestaciones escritas depende de la circunstancia, objetivamente verificable y que se deja a la valoración del intérprete llamado a aplicar la norma en cuestión, de que esos documentos se utilicen como medio de comunicación y, por lo tanto, como elementos estructurales de las manifestaciones en cuestión o, más concretamente, como meros instrumentos para la reproducción mecánica de hechos o cosas.

En tales condiciones, el art. 20, ap. 1-bis, C.a.d. aclara oportunamente que el documento informático sin firma no tiene necesariamente la admisibilidad probatoria de las reproducciones mecánicas, como podría dar a entender la única referencia a la eficacia probatoria del documento informático contenida originalmente en el art $5,1 .^{\circ}$ apartado, decreto del Presi-

${ }^{33}$ La versión actualmente en vigor se ha introducido por decreto legislativo 13 diciembre 2017, n. 217.

${ }^{34}$ Giusella Finocchiaro, «Ancora novità in materia di documento informatico: le recenti modifiche al Codice dell'amministrazione digitale», Contratto e impresa (2011): págs. 495 y siguentes, especialmente pág. 500. 
dente della Repubblica n. ${ }^{\circ}$ 513/1997 ${ }^{35}$, sino que podría valer como un documento privado sujeto a la prudente valoración del intérprete, aunque no sea un documento firmado según el art. 2702 c.c.

De hecho, debe tenerse en cuenta que la primera de las valoraciones correspondientes al intérprete del art. 20 cit. es precisamente la verificación de si el documento informático sujeto a su examen:

a) forma parte de la estructura de una manifestación, es decir, si se trata de un documento informático declarativo sujeto a interpretación, en otras palabras, un escrito informático;

b) o se trata de la mera reproducción informática de hechos, es decir, un documento que no sirve para exteriorizar la voluntad o el pensamiento de alguien (por lo tanto, no puede considerarse sujeto a interpretación, porque no «quiere decir» nada) y que existe de manera independiente y autónoma con respecto a los hechos que, a través de él, pretenden probarse (por lo tanto, a ese efecto, sólo puede considerarse sujeto a inferencias).

La segunda hipótesis comprende no solo la representación informática de hechos distintos de una declaración, sino aquella de una declaración también, si resulta que ésta ha sido formulada con independencia de su reproducción en el documento. Constituyen ejemplos de dichos casos la grabación de sonido y/o visual de una conversación que no pretende comunicarse a terceros mediante el documento que lo representa (prueba de una declaración oral), o el vídeo que muestra la creación de otro documento escrito destinado a constituir la forma autónoma de una declaración (prueba de una declaración escrita o, por lo menos, de la actividad de documentación destinada a una declaración escrita).

Si el documento informático forma parte del cuerpo de una declaración, se aplican a aquel documento las disposiciones sobre la admisibilidad sustancial de la documentación informática y sobre la relevancia probatoria de los documentos informáticos. Si resulta que tal manifestación se hizo de modo independiente a la de su reproducción en el documento, el documento es ajeno a la perfección del supuesto declarativo, que se limita a representar, y sólo se le aplican las disposiciones relativas a la relevancia probatoria

35 En este sentido, de hecho, v. Giusella Finocchiaro, «Ancora sull'efficacia probatoria del documento informatico non sottoscritto, commento a Cass. civ., sez. lav., sent. 11 maggio 2005, n. 9884», Diritto dell'Internet (2005): págs. 5633 y siguientes, especialmente págs. 566; y también Giusella Finocchiaro, «La firma digitale», en Commentario Scialoja-Branca, artt. 2699-2720 - Supplemento (Bologna-Roma: Zanichelli-Il Foro Italiano, 2000) págs.7071; Giusella Finocchiaro, Firma digitale e firme elettroniche. Profili privatistici (Milano: Giuffrè, 2003), págs.117-118. 
de las reproducciones informáticas. En tales condiciones, si el hecho reproducido es una manifestación, a tal manifestación deben aplicárseles las normas relativas a la admisibilidad sustancial y probatoria propias de la forma con la que aquella manifestación resulte autónomamente hecha (incluyendo el procedimiento de interpretación para la averiguación del significado).

Este enfoque demuestra la coherencia de la disciplina contenida en el C.a.d. y permite concluir que en el caso de los escritos informáticos sin una firma que los hace similares a los documentos firmados tradicionales, el ordenamiento opta por atribuir a la prudente apreciación del intérprete su valoración a efectos probatorios, sustrayéndolos:

- tanto del régimen de los documentos firmados previsto en el art. 2702 c.c. (que, por contra, está reservado a los documentos firmados con firma electrónica avanzada, cualificada o digital o «cuando, en todo caso, se constituyan, tras la identificación informática de su autor, mediante un procedimiento que cumpla con los requisitos establecidos por la Agenzia per l'Italia Digitale, de conformidad con el artículo 71 C.a.d., «de forma que se garantice la seguridad, integridad e inmodificabilidad del documento y, de forma clara e inequívoca, su trazabilidad hasta el autor» - art. 20, apartado 1. ${ }^{\circ}$ bis, C.a.d.),

- como al de las reproducciones mecánicas del art. 2712 c.c., reconstruido por los intérpretes (que, por contra, está reservado sólo a las reproducciones informáticas de hechos y de cosas — art. 2712 c.c., modificado por el art. 23 quater C.a.d., introducido por el art. 16, 2. ${ }^{\circ}$ apartado, lect. $a$, d.lgs. 30 diciembre de 2010, n. 235).

De hecho, en coherencia con las consideraciones efectuadas:

a) por una parte, al no poder atribuirse razonablemente la admisibilidad propia de la forma escrita a un documento que en realidad no se ha redactado ni utilizado para manifestar algo, el ordenamiento se limita a regular la eficacia probatoria del documento informático representativo mediante el art. 2712 c.c. (que se refiere al supuesto de las reproducciones mecánicas, en el que los hechos del documento afectan en cuanto a la prueba, pero no en cuanto a la propia existencia del hecho a probar), dejando que la eficacia sustancial del hecho representado en él quede sujeta a las disposiciones aplicables en el momento, con independencia de la utilización de la herramienta telemática;

b) por otra parte, en lo que respecta a los distintos supuestos de los escritos informáticos, en los que los hechos del documento afectan no solo a la prueba, sino en cuanto a la propia existencia del hecho a 
probar, el legislador regula tanto la admisibilidad sustancial como la eficacia probatoria, dejando ambas, como regla general, a la libre valoración del intérprete (el art. 20, apartado 1-bis, C.a.d.);

c) si el documento está firmado, el intérprete no podrá considerar discrecionalmente que la firma es ineficaz o inadmisible como prueba por el hecho de estar en formato electrónico, o no estar basada en un certificado cualificado expedido por un prestador de servicios de certificación acreditado, o tampoco por haber sido redactado por un dispositivo para la creación de una firma segura (antes art. 5 Dir. 1999/93/CE sobre la firma electrónica y ahora art. 25 Reglamento eIDAS), sino que deberán tenerse en cuenta sus características objetivas de seguridad, integridad e inmodificabilidad (art. 20, apartado $1 .^{\circ}$ bis, C.a.d.) y verificarse el cumplimento y la concurrencia de al menos uno o más de los requisitos destinados a garantizar la identificabilidad del autor, así como la integridad e inmodificabilidad del documento, de conformidad con las normas técnicas (llamadas «Linee guida», es decir «Directrices») sobre la redacción, transmisión, conservación, copia, duplicación, reproducción y validación temporal de los documentos informáticos, y aquéllas sobre la generación, colocación y verificación de cualquier tipo de firma electrónica avanzada (arts. 20, apartados 1-bis y 3, y 71 C.a.d.);

d) en cuanto a la eficacia sustancial del supuesto concreto, se otorga una especial relevancia a los documentos informáticos firmados con firma electrónica cualificada o con firma digital, que son las únicas firmas electrónicas que pueden válidamente emplearse para los documentos privados referidos por el art. 1350, $1 .^{\circ}$ apartado, $n .{ }^{\circ}$ $1-12$, c.c. (los demás actos indicados por la ley que, de conformidad con el art. 1350, . $^{\circ} 13$, del Código Civil italiano, deben realizarse mediante escritura pública o privada pueden válidamente constituirse mediante los demás procedimientos a que se refiere la primera frase del artículo 20, apartado 1 ter bis); sólo si la firma es autentificada por notario o por otro funcionario público autorizado al efecto los documentos podrán ser firmados con cualquier otra firma electrónica o cualquier otro tipo de firma avanzada, así como con la obtención digital de la firma autógrafa (art. 21, ap. 2. ${ }^{\circ}$ bis, C.a.d.);

e) a nivel probatorio, se otorga una especial relevancia a los documentos firmados con firma electrónica avanzada, cualificada o digital, cuando se redacten de acuerdo con las Directrices ya expuestas: tales documentos tendrán la eficacia prevista en el artículo 2702 c.c. y se presumirá que el uso del dispositivo de firma utilizado para redactarlos es atribuible al titular, salvo que se demuestre lo contrario (art. 21, 2. ${ }^{\circ}$ apartado, C.a.d.) 


\section{Los nuevos documentos en derecho europeo de consumo}

La consideración de la disciplina italiana de la prueba documental a la luz del debate sobre la eficacia probatoria del documento informático, ayuda decisivamente en la elección, también a efectos de la legislación europea, entre la noción de escritura contenida en el Interpretation Act de 1978 y la propuesta por el art. 1.11 de los Principios del Unidroit.

En efecto, la distinción entre «documentos declarativos» (como las escrituras del derecho italiano) y «documentos meramente representativos» (como las reproducciones mecánicas a que se refiere el artículo 2712 del Código Civil italiano) muestra claramente que, a los efectos para los que se prescriben los documentos escritos, lo que realmente cuenta en el derecho privado europeo no es tanto la forma de comunicación (escrita, oral o por medio de otros símbolos convencionales (como, por ejemplo, un guiño con la cabeza para dar su consentimiento), sino la realización de dicha comunicación mediante la entrega de un medio duradero que permita al receptor conocer la declaración y conservar las pruebas.

En estas condiciones, entre las dos nociones de escritura consideradas en la introducción, la que ofrece el art. 1.11 Principios Unidroit es ciertamente preferible a la más obsoleta, contenida en el Interpretation Act de 1978.

A diferencia de lo que ha sido argumentado por la doctrina que lo ha tratado, esta definición incorpora la idea, ya muy extendida entre los operadores, de que el concepto ahora ampliado de escritura incluye no sólo los textos sin firma, o sin otras formalidades particulares aseverativas de su origen (como la necesidad de que el autor escriba a mano, o de que la firma de los testigos se fije en el documento, o de que se fije una firma electrónica certificada ${ }^{36}$ ), sino también los registros sonoros, visuales y audiovisuales a que se refiere la definición de documento electrónico que ofrece el Reglamento eIDAS, así como la documentación de otras formas de comunicación que no reproducen palabras de forma visible, también en un medio que no sea un documento electrónico, siempre que el documento sea el medio para hacer la declaración.

De hecho, también en el Derecho europeo, el concepto de documento ha evolucionado de manera explícita en el mismo sentido que se ha expuesto hasta ahora.

Una clara referencia en este sentido es la evolución de las disposiciones relativas a uno de los derechos fundamentales del consumidor, como es el de recibir información escrita, específica y puntual sobre determinados as-

$36 \mathrm{~V}$. Vogenauer, «Article $1.2 \ldots », 162$. 
pectos que el legislador europeo ha considerado relevantes y que son relativos a la fase precontractual o contractual de su relación con un profesional.

A este respecto, inicialmente la Directiva 85/577/CEE del Consejo de 20 de diciembre 1985 «referente a la protección de los consumidores en el caso de contratos negociados fuera de los establecimientos comerciales», tras declarar «que conviene conceder al consumidor un derecho de rescisión [rectius: derecho de desistimiento n.d.r.] durante un período de siete días, como mínimo, con el fin de ofrecerle la posibilidad de considerar las obligaciones que resultan del contrato» (5. ${ }^{\circ}$ considerando) y que «es preciso adoptar las medidas adecuadas con el fin de que el consumidor esté informado por escrito de dicho plazo de reflexión» ( $6 .^{\circ}$ considerando), disponía que el profesional está «obligado a informar por escrito al consumidor» de su derecho de desistimiento del contrato en el plazo previsto por la ley, así como del nombre y dirección de la persona frente a la que pueda ejercer tal derecho (art. 4).

Posteriormente, empero, la Directiva 97/7/CE del Parlamento Europeo y del Consejo del 20 mayo de 1997 «relativa a la protección de los consumidores en materia de contratos a distancia», tras considerar «que la información difundida por determinadas tecnologías electrónicas tiene a menudo un carácter efímero en la medida en que no se recibe sobre un soporte duradero; que resulta necesario que se hagan llegar al consumidor, por escrito y con la debida antelación, los datos necesarios para la correcta ejecución del contrato» (13. ${ }^{\circ}$ considerando), dividió el deber de información en dos exigencias, potencialmente distintas:

a) la primera consistía en una comunicación por la que «previamente a la celebración de cualquier contrato a distancia, y con la antelación necesaria», el profesional debía facilitar al consumidor sin restricción de forma (y, por lo tanto, también en una forma que, utilizando el léxico del $13 .^{\circ}$ considerando, podría definirse como «efímera») (art. 4);

b) la segunda se debe hacer efectiva facilitando la información al consumidor «por escrito o mediante cualquier otro soporte duradero a su disposición» «a su debido tiempo durante la ejecución del contrato y, a más tardar, en el momento de la entrega cuando se trate de bienes, a menos que se haya facilitado ya la información al consumidor antes de la celebración del contrato» (art. 5).

De este modo, el legislador comunitario estableció explícitamente una equivalencia entre la información facilitada por escrito y aquélla facilitada en otro soporte duradero a disposición del destinatario y accesible para él.

Finalmente, el art. 2, ap. 10 de la Directiva 2011/83/UE del Parlamento Europeo y del Consejo de 25 octubre de 2011 «sobre los derechos 
de los consumidores, por la que se modifican la Directiva 93/13/CEE del Consejo y la Directiva 1999/44/CE del Parlamento Europeo y del Consejo y se derogan la Directiva 85/577/CEE del Consejo y la Directiva 97/7/CE del Parlamento Europeo y del Consejo» ha ofrecido una definición oficial del término «soporte duradero», describiéndolo como «todo instrumento que permita al consumidor o al comerciante almacenar información que se le transmita personalmente de forma que en el futuro pueda recuperarla fácilmente durante un período de tiempo acorde con los fines de dicha información y que permita la reproducción de la información almacenada sin cambios»

A la luz de esta definición, la Directiva en cuestión ha definido las modalidades para documentar determinadas manifestaciones o informaciones que en algunas ocasiones deben ser facilitadas por parte del consumidor y en otras por parte del comerciante.

A este respecto, de hecho, ha aclarado que «el consumidor debe seguir siendo libre de desistir del contrato empleando sus propios términos, siempre que su declaración de que quiere desistir del contrato dirigida al comerciante sea inequívoca»; que «una carta, una llamada telefónica o la devolución de los bienes acompañadas de una declaración clara podría satisfacer este requisito, si bien la carga de la prueba de haber desistido en los plazos establecidos por la Directiva debe recaer sobre el consumidor»; y que "por este motivo, redundará en interés del consumidor la utilización de un soporte duradero al comunicar su desistimiento al comerciante» (44..$^{\circ}$ considerando). Por este motivo, ha dispuesto, por un lado, que el consumidor puede presentar eficazmente cualquier declaración explícita de su decisión de desistir del contrato y que la carga de la prueba relativa al ejercicio de este derecho recae sobre el consumidor; y, por otro lado, también que «el comerciante comunicará sin demora al consumidor en un soporte duradero el acuse de recibo de dicho desistimiento» una vez que el consumidor, ejerciendo una opción ofrecida por el profesional, haya cumplimentado y enviado por vía electrónica la declaración de desistimiento (art. 11).

El legislador europeo también ha aclarado que «el consumidor debe solicitar de forma expresa la prestación del servicio antes de que finalice el plazo de desistimiento mediante una solicitud expresa y, en el caso de un contrato celebrado fuera del establecimiento mercantil, deberá hacerlo en un soporte duradero» y que «del mismo modo, el comerciante debe informar al consumidor, utilizando un soporte duradero, de toda obligación de abonar la parte proporcional del coste de los servicios ya prestados» $\left(50\right.$. $^{\circ}$ considerando). Por este motivo, ha dispuesto que «en caso de que un consumidor desee que la prestación de servicios o el suministro de agua, gas, electricidad - cuando no estén envasados para la venta en un volumen de- 
limitado o en cantidades determinadas - , o calefacción mediante sistemas urbanos, dé comienzo durante el plazo de desistimiento previsto en el artículo 9, apartado 2, el comerciante exigirá que el consumidor presente una solicitud expresa en tal sentido en un soporte duradero» (art. 7.3).

Finalmente, la Directiva en cuestión también ha dispuesto que «en los contratos a distancia, el comerciante facilitará al consumidor la información exigida en el artículo 6, apartado 1 [es decir aquella que debe facilitarle antes que sea vinculado por el contrato, n.d.r.], o la pondrá a su disposición de forma acorde con las técnicas de comunicación a distancia utilizadas, en términos claros y comprensibles» y que «siempre que dicha información se facilite en un soporte duradero deberá ser legible».

Téngase en cuenta que si el profesional facilita «en un soporte duradero» la información al consumidor antes de quedar vinculado por un contrato a distancia, esta información «shall be legible», expresión que también se da en italiano con la fórmula «devono essere leggibili» y que también en español se traduce con la expresión «deberá ser legible» (art. 8, en relación al art. 6.1). Sin embargo, precisamente a la luz de lo que se ha argumentado hasta ahora, cabe entender que el término «legible» en este caso no tiene el mismo significado que la expresión «representing or reproducing words in visible form» en el Interpretation Act de 1978.

De hecho, en el contexto del art. 8, «legible» no puede significar que la información deba imprimirse en un soporte con símbolos comprensibles para la lectura, ya que este deber ya se impone de forma general en el primer inciso del mismo artículo, cuando se establece que la información se debe facilitar «de forma acorde con las técnicas de comunicación a distancia utilizadas, en términos claros y comprensibles».

Por otra parte, la expresión debe entenderse en el sentido de que pueda comprenderse fácilmente a la luz de la definición de «soporte duradero» que ofrece el art. 2, ap. 10, Dir. 2011/83/UE, así como la que ya en su día se estableció por el art. 5, Dir. 1997/7/CE en el mismo sentido. De estos elementos se desprende que la información debe proporcionarse a través de un medio que:

a) por un lado, permita al destinatario «almacenar información que se le transmita personalmente de forma que en el futuro pueda recuperarla fácilmente durante un período de tiempo acorde con los fines de dicha información» (art. 2, n. ${ }^{\circ}$ 10, Dir. 2011/83/UE, parte primera): en otras palabras, la información debe facilitarse a través de un soporte que permanezca «a su disposición» de forma duradera (art. 5 Dir. 1997/7/CE);

b) por otro lado, debe permitir al destinatario «la reproducción de la información almacenada sin cambios» (art. 2, n. ${ }^{\circ}$ 10, Dir. 2011/83/ 
UE, parte segunda): en otras palabras, la información se debe facilitar mediante un soporte «que sea accesible para el».

En este contexto, «legible» tiene el mismo sentido del término «accesible» a la luz del art. 5 Dir. 97/7/CE, en el que «accesible» no sólo significa que el documento deba estar materialmente a disposición del consumidor, porque esto ya se expresa cuando se establece que el soporte debe estar «a su disposición», sino que éste debe permitir al destinatario la «reproducción de la información almacenada sin cambios», y por lo tanto, comprensible en el sentido de descifrable y, en el caso de documentos informáticos, compatibles con los estándares de interoperabilidad y software de lectura de los archivos adecuadamente remitidos o, alternativamente, que sean legibles mediante la puesta a disposición del destinatario de la aplicación necesaria para la lectura del archivo a través de un dispositivo electrónico apto para almacenarlo.

\section{El impacto de los nuevos documentos europeos en el Derecho italiano}

En aplicación de estas normas, el art. 45.1, lect. l, del Codice del consumo italiano también ha sido modificado por el d.lgs. de 21 febrero 2014, n. ${ }^{\circ} 21$ y, por lo tanto, el Derecho italiano ahora también contempla una noción explícita y oficial de «soporte - o medio- duradero», que debe entenderse como «todo instrumento que permita al consumidor o al comerciante almacenar la información que se le dirige personalmente, de manera que pueda acceder a ésta en el futuro por un periodo de tiempo adecuado a las finalidades para las que están destinados y que permita la reproducción sin cambios de la información almacenada».

Esta noción es la utilizada por el legislador italiano para definir las modalidades de cumplimiento de los deberes de información (art. 48, lect. $a, 50.1,50.2,50.4$, letras. $a$ y $b, 51.1$ y 51.6 ), otros deberes declarativos (art. 54.3), de manifestaciones contractuales (art.50.2, 50.4, letra $b$ ) y cargas de declaración (art. 50.3).

De este modo, dicha actualización confirma que, de manera alternativa y equivalente al documento redactado mediante el uso de símbolos gráficos (escrito, en sentido estricto), es posible utilizar el creado mediante una grabación audiovisual, o meramente de sonido, etc. (escrito, en sentido amplio).

También debe interpretarse en este sentido el art. 20, apartado 1-bis, C.a.d. que, como es sabido, en cuanto al documento informático declarativo establece que «la idoneidad del documento informático para satisfacer 
el requisito de la forma escrita y su valor probatorio se puede evaluar líberamente en juicio, teniendo en cuenta sus características objetivas de seguridad, integridad e inmutabilidad». Cabe considerar, de hecho, que a los efectos de esta disposición el documento informático declarativo puede ser redactado no solo a través del almacenamiento de un archivo de texto, sino también a través de una grabación de sonido o visual.

La extensión de la noción de documento escrito no llega a incluir las representaciones efímeras. De hecho, aunque el C.a.d. habla de «documento analógico» para designar «la representación informática de actos, hechos o datos jurídicamente relevantes» (art. 1, letra. q), el documento no debe confundirse con la representación que se pueda extraer de él. Tanto porque en el léxico del legislador una cosa son los medios de prueba (cfr. art. 202 y siguientes c.p.c.) y otra es la prueba que se basa en ellos, es decir, la representación de los hechos basados en ellos (cfr. art. 116 c.p.c., así como arts. 2700, 2702, 2007, 2708 c.c.) ${ }^{37}$. Como porque, en todo caso, la representación de un hecho puede tener un carácter transitorio incompatible con la necesidad de tener una representación permanente, que, por otro lado, constituye el núcleo de la normativa sobre la relevancia probatoria de los documentos. En este sentido, el legislador lo hizo bien a la hora de modificar la fórmula original con la que definió el documento informático como «la representación informática de actos, hechos o datos jurídicamente relevantes» con la mejor expresión según la cual el documento informático es «el documento electrónico que contiene la representación informática de actos, hechos o datos jurídicamente relevantes» (art. 1, letra $p$, C.a.d.).

En definitiva, las definiciones del art. 1, letras $p$ y $q$, cit. deben entenderse en el sentido de que los documentos son soportes duraderos que comportan una representación digital o analógica de forma permanente, de modo que se pueda conocer la definición de las cosas representativas de hechos ${ }^{38}$.

En estas condiciones, así como que una videollamada o una videoconferencia permiten la representación de hechos o cosas (y, por lo tanto, también las actividades de comunicación y declaración), pero no generan documentos, a menos que aquellas representaciones no se graben en un soporte duradero adecuado (cfr. art. 51.6 y 51.7 del Codice del consumo); de la misma manera, una declaración efectuada a través de medios informáticos o telemáticos o una representación de hechos o cosas no constituye documento informático si no se almacena en un soporte duradero susceptible de

37 Vittorio Denti, La verificazione delle prove documentali (Torino: Utet, 1957), págs. 2 , 5-6, así como págs. 50 y siguientes.

${ }^{38}$ Francesco Carnelutti, La prova civile -Parte generale-Il concetto giuridico di prova (reimpresión Milano: Giuffrè, 1992), págs. 54 y siguientes. 
ser conservado de modo permanente, y que permita reproducir la manifestación o representación incluso con posterioridad ${ }^{39}$.

Y, como la forma escrita constituye la modalidad adecuada de la manifestación hecha a través de la redacción de un documento y su posterior emisión en beneficio del destinatario ${ }^{40}$, si falta la actividad de documentación, una declaración efectuada en forma telemática no colma el requisito de forma escrita, ni siquiera aunque se haga mediante el uso de símbolos alfanuméricos propios de la escritura tradicional.

\section{Conclusiones}

En definitiva, la distinción específica que hace la legislación italiana entre «escritos» $\mathrm{y}$ «reproducciones mecánicas» permite extraer una serie de conclusiones que, sin duda alguna, son de gran utilidad para interpretar la normativa europea sobre la escritura en general, así como los documentos electrónicos y las obligaciones de información en materia de protección a los consumidores en particular.

En primer lugar, destaca que los mismos requisitos a los que responde el uso de un documento escrito entendido en el sentido más tradicional, es decir, el resultado del acto de escribir, también pueden satisfacerse con la redacción de documentos declarativos en soportes duraderos en los que la actividad de documentación no se realice escribiendo letras del alfabeto o signos análogos, sino a través de grabaciones de sonido o visuales, de manifestaciones orales, gestuales, o de otros símbolos.

Esto lleva a considerar que, a los efectos de la individualización del régimen jurídico aplicable, la línea divisoria entre los documentos escritos y los que no lo son, no puede depender eficazmente de una circunstancia meramente extrínseca y contingente de si se trata o no del resultado de una acción consistente en trazar sobre una superficie adecuada los signos gráficos

39 Cfr. Luigi Paolo Comoglio, «Le prove», en Trattato Rescigno, Vol. XIX, Tutela dei diritti, t. I, (Torino: Utet, 1997), págs. 177 y siguientes, especialmente pág. 374; Salvatore Sica, Atti che devono farsi per iscritto, en Commentario fondato da P. Schelsinger e diretto da F.D. Busnelli, sub art. 1350 (Milano: Giuffrè, 2003), 73; Ricci, Scritture private..., págs. 89 y siguientes; Elisabeth Joly-Passant, L'écrit confronté aux nouvelles technologies, (Paris: L.G.D.J., 2006), 20-21. Contra v. Cesare Massimo Bianca, «I contratti digitali», Studium iuris (1998): págs. 1035 y siguientes, especialmente pág. 1036; así como Francesco Gerbo, «Documento», en Diritto civile, ed. por Martuccelli y Pescatore, págs. 678 y siguientes, especialmente pág. 682.

40 Entre los elementos estructurales de los documentos privados se encuentra también «la cosa destinata a recepire la scrittura, ossia l'entità fisica, il veicolo reale o lo strumento rappresentativo della documentazione» (Comoglio, Le prove..., 335). 
que pertenecen a un determinado sistema de escritura, de modo que quien conozca dicho sistema pueda leerlos e interpretar su significado, sino del argumento, racionalmente más cualificado, de si se trata o no de medios para reconocer de forma duradera la expresión de la voluntad o del pensamiento de su autor.

De ello se derivan mejores criterios de calificación jurídica de la forma escrita y de los documentos escritos útiles a los efectos de la aplicación de la normativa correspondiente.

En particular, con respecto al documento entendido como acto de escritura, es forma escrita toda forma de comunicación que permita compartir y almacenar lo que se expresa de forma tangible. A la forma escrita así entendida se opone toda otra forma efímera de comunicación, es decir, toda forma de comunicación que, contrariamente a la primera, no permita almacenar en forma tangible lo que se ha comunicado. En esta perspectiva, es pues preferible la noción de documento ofrecida por el art. 1.11 de los Principios Unidroit de 2016, y ya por el art. 1.10 de la edición de 1994, porque no parece ni actual, ni útil el criterio de distinción ofrecido por el Interpretation Act de 1978 del Reino Unido, excepto en los casos particulares en los que quiera asegurarse una forma de comunicación en modo visible por razones específicas, como podría ser, por ejemplo, el caso emblemático de manifestaciones o documentos destinados a aparatos de lectura sin altavoces o destinados a personas sin audición.

Con respecto al documento entendido como resultado del escribir, lo que se ha concluido sobre la forma escrita se deduce directamente también que todos los documentos que se utilizan para declarar algo son documentos, o «documentos declarativos» (en otras palabras, cualquier actividad de documentación de una manifestación genera un documento escrito). Éstos se contraponen a los documentos que reproducen uno o más aspectos de hechos o cosas cuya existencia no depende de la existencia de los documentos que los representan y que, por lo tanto, se podrían denominar «documentos meramente representativos».

En esta perspectiva, los documentos que constituyen el resultado de la aplicación a un soporte material de automatismos que dependen directamente de la interacción entre el aparato que redacta el documento y una o más características de la realidad que éste representa (fotografías, grabaciones de sonido, grabaciones vídeo, moldes, gráficos de electrocardiograma o de un sismógrafo, etc.) pueden pertenecer tanto a la categoría de los documentos declarativos o documentos, como a la de los documentos meramente representativos. De hecho, pertenecen a la primera categoría cuando se utilicen para manifestar algo; en cambio, pertenecen a la segunda categoría cuando reproduzcan uno o más aspectos de hechos o de cosas cuya existencia es independiente tanto de su redacción, como de su uso. 
Esta conclusión es aplicable a los documentos informáticos, que pueden ser de naturaleza declarativa o meramente representativa:

a) los documentos informáticos declarativos son documentos escritos y, si están provistos de firma digital o firma electrónica avanzada, son documentos privados eficaces, en cuanto a su forma, a los efectos del art. 1350 c.c. (traslación de derechos reales inmobiliarios y similares), y admisibles, en términos de prueba, al amparo y a los efectos del art. 2702 c.c.; de lo contrario, quedarán sujetos a la prudente valoración del juez, tanto a los efectos de su admisibilidad para los efectos de las demás disposiciones en materia de forma escrita, como a los efectos de la prueba;

b) los documentos informáticos meramente representativos nunca son documentos escritos y, a título probatorio, integran la noción de «reproducciones mecánicas» en el sentido del art. 2712 c.c.

\section{Bibliografia}

Abel Lluch, Xavier. La valoración de la prueba en el proceso civil. Madrid: Wolters Kluwer España, 2014.

Benedetti, Giuseppe. «Parola scritta e parola telematica nella conclusione dei contratti». En Scrittura e diritto, Milano: Giuffrè, 2000, 75-91.

Bianca, Cesare Massimo. «I contratti digitali». Studium iuris 4 (1998), 1035-1051:

Bianca, Cesare Massimo, Renato Clarizia, Vincenzo Franceschelli, Franco Gallo, Lucio Valerio Moscarini, Alessandro Pace y Salvatore Patti. «Formazione, archiviazione e trasmissione di documenti con strumenti informatici e telematici - commentario del decreto del Presidente della Repubblica 10 novembre 1997, n. 513». Nuove leggi civili commentate 23, n. ${ }^{\circ}$ 3-4 (2000): 633-846.

Carnelutti, Francesco. Sistema del diritto processuale civile, vol. I. Padova: CEDAM, 1936.

Carnelutti, Francesco. Teoria generale del diritto. Napoli: ESI, 1951, 3. a ed.

Carnelutti, Francesco. La prova civile - Parte generale - Il concetto giuridico di prova. Reimpresión Milano: Giuffrè, 1992

Comoglio, Luigi Paolo. «Le prove». En Trattato Rescigno, Vol. XIX, Tutela dei diritti, t. I: Torino: Utet, 1997.

Comoglio, Luigi Paolo. Le prove civili. Torino: Utet Giuridica (2010, 3. ${ }^{a}$ ed).

Cruz Rivero, Diego Juan. La firma electrónica reconocida - Análisis de los requisitos del articulo 3.3 de la Ley 59/2003, de 19 de diciembre, de firma electrónica. Madrid: Consejo General del Notariado, 2006.

Denti, Vittorio. La verificazione delle prove documentali. Torino: Utet, 1957.

De Santis, Francesco. Il documento non scritto come prova civile. Napoli: ESI, 1988.

Dickie, John. Internet and Electronic Commerce Law in the European Union. 1999. Oxford: Hart Publishing, 1999. 
Díez-Picazo, Luís, Antonio Gullón, Sistema de derecho civil, vol. II, t. I. Madrid: Editorial Tecnos, 2017, 11. . ed.

Falzea, Angelo. «Manifestazione - teoria generale». En Enc. dir., vol. XXV. Milano: Giuffrè: 442-476.

Flint, David. «Electronic Communications Bill - Early Closing Day for E-Commerce?». Business Law Review 20 (1999): 248-251

Flint, David. «Promoting Electronic Commerce: Consultation on Draft Legislation and the Government's Response to the Trade and Industry Committee's Report». Business Law Review 20 (1999): 282-284

Finocchiaro, Giusella. La firma digitale. Bologna: Zanichelli - Roma: Il Foro Italiano, 2000.

Finocchiaro, Giusella. Firma digitale e firme elettroniche. Profili privatistici. Milano: Giuffrè, 2003.

Finocchiaro, Giusella. «Ancora novità in materia di documento informatico». Contratto e impresa 27, n. ${ }^{\circ} 2$ (2011): 495-504.

Gentili, Aurelio. «Documento informatico». En Enc. dir., Annali V. Milano: Giuffrè: 629-643

Gerbo, Francesco. «Documento». En Diritto civile, ed. por Martuccelli y Pescatore: 678-691,

Giampiccolo, Giorgio. «Dichiarazione recettizia». En Enc. dir., vol. XII. Milano: Giuffrè (1964): 384-391.

Irti, Natalino. Studi sul formalismo negoziale. Padova: CEDAM, 1997.

Irti, Natalino. Idola libertatis. Milano: Giuffrè, 1985.

Joly-Passant, Elisabeth. L'écrit confronté aux nouvelles tehnologies. Paris: LGDJ, 2006.

Kötz, Heinz. European Contract Law. New York: Oxford University Press, 2017, $2 .^{\mathrm{a}} \mathrm{ed}$.

Laserra. Giorgio. La scrittura privata. Napoli: Jovene, 1959.

Liebman, Enrico Tullio. Manuale del processo civile, Vol. II. Milano: Giuffrè, 1981, 4. ${ }^{\mathrm{a}}$ ed.

Lloyd, Ian. Cyber Law in the United Kingdom. London: Wolters Kluwer, 2017, 3 .' ed.

Mankowski, Peter. «Information and Formal Requirements in EC Private Law». European Review of Private Law 6, 2005: 779-796.

Mason, Stephen. Electronic Signatures in Law. London: Institute of Advanced Legal Studies, School of Advanced Study, 2016.

Merone, Aniello. Il disconoscimento delle prove documentali. Torino: Giappiche1li, 2018.

Montesano, Luigi. «Sul documento informatico come rappresentazione meccanica nella prova civile e nella forma negoziale». Diritto dell'informazione $e$ dell'informatica, n. ${ }^{\circ}$ 4-5 (1987): 23-32.

Orlandi, Mauro. La paternità delle scritture. Milano: Giuffrè, 1997.

Patti, Salvatore. «Prova documentale», en Commentario del Codice Civile ScialojaBranca, editado por Francesco Galgano, artt. 2699-2720. Bologna: Zanichelli Roma: Il Foro Italiano, 1996. 
Patti, Salvatore. «Prove». En Commentario del Codice Civile e codici collegati Scialoja-Branca-Galgano, artt. 2697-2739. Bologna: Zanichelli, 2015.

Pavoni, Giovanni. La scrittura privata nel diritto commerciale. Roma: Athenaeum, 1914.

Ricci, Francesco «Teleshopping e vendite a distanza nella disciplina delle vendite aggressive». En Materiali e commenti sul nuovo diritto dei contratti, ed. por Giuseppe Vettori: Padova: Cedam, 1999: 258-293.

Ricci, Francesco. «L'informazione del consumatore e l'inefficacia delle clausole occulte». Temi romana 48 (2000): 829-840.

Ricci, Francesco. «Informazioni per il consumatore e volontarietà del contratto telematico». Temi romana 48 (2000): 841-847.

Ricci, Francesco. Scritture private e firme elettroniche: Milano: Giuffrè, 2003.

Ricci, Francesco. «Firma digitale», en Diritto civile, ed. por Silvio Martuccelli y Valerio Pescatore (Milano: Giuffrè, 2011): 783-797

Ricci, Francesco. «Le clausole vessatorie nei contratti on line». Contratto e impresa. Europa 19, n. ${ }^{\circ} 2$ (2014): 651-689

Romano, Alberto A. «Il disconoscimento della prova documentale». En Studi in onore di P. Schlesinger, vol. V. Milano: Giuffrè, 2004: 3923-3940.

Santoro-Passarelli, Francesco. Dottrine generali del diritto civile. Napoli: Jovene, 2016, 9. ${ }^{\mathrm{a}} \mathrm{ed}$.

Schlesinger, Pietro. «Dichiarazione (teoria generale)». En Enc. dir., Vol. XII. Milano: Giuffrè, 1964: 371-384

Schofield, Damian. «The use of computer generated imagery in legal proceedings». Digital Evidence and Electronic Signature Law Review13 (2016): 3-25.

Sharon, Harvey y Julian Newman. «Contracts by electronic mail: some issues explored». Computer Law \& Security Review (1988): 2-6.

Sica, Salvatore. Atti che devono farsi per iscritto. En Commentario fondato da P. Schelsinger e diretto da F.D. Busnelli, sub art. 1350. Milano: Giuffrè, 2003.

Torres Lana, José Ángel. «Forma del negocio y nuevas teconologías». Revista de Derecho Privado (2004): 489-523.

Vogenauer, Stefan. «Article 1.2 (No form required», en Commentary on the Unidroit Principles of International Commercial Contracts (PICC), editado por Stefan Vogenauer (Oxford: Oxford University Press, 2017, 2 a ed.): 159-162.

\section{Acerca del autor}

Francesco Ricci, Doctor en Derecho Contractual y Economía de la Empresa y Abogado, es profesor titular de Derecho Privado en la Universidad L.U.M. Jean Monnet de Bari - Casamassima y profesor de Derecho Privado Europeo en la Universidad L.U.I.S.S.S. Guido Carli de Roma. Fue miembro del consejo de profesores de la «International School of Doctorate in Law and Economics» «Tullio Ascarelli» de la Universidad Roma Tre de Roma y actualmente es miembro del consejo de profesores del «International PhD in «General Theory of Trial: Administrative, Civil, Constitutional, 
Criminal and Fiscal» de la L.U.M. Jean Monnet University of Bari - Casamassima, de acuerdo con la Universidad John Naisbitt de Beograd (Serbia) y la Universidad de Europa Sudoriental - Macedonia. Es autor de numerosas publicaciones, entre las que destacan tres libros ( $\ll$ Scritture private e firme elettroniche» - 2004, «Due diligence e responsabilità»- 2008 y «Beni di consumo e disciplina delle vendite aggressive» - 2013) y numerosos artículos, entre otros, sobre delitos civiles, información precontractual, formularios y pruebas contractuales, contratos tipo, ventas, registros inmobiliarios, pruebas documentales, protección del consumidor, comercio electrónico, organizaciones deportivas, ADR.

\section{About the author}

Francesco Ricci, PhD in Contract Law and Business Economics and Lawyer, is full professor of private law at the L.U.M. Jean Monnet University of Bari - Casamassima and professor of European private law at the L.U.I.S.S.S. Guido Carli University of Rome. He was a member of the board of professors of the «International School of Doctorate in Law and Economics "Tullio Ascarelli"» at the University Roma Tre in Rome and is currently a member of the board of professors of the "International $\mathrm{PhD}$ in "General Theory of Trial: Administrative, Civil, Constitutional, Criminal and Fiscal"» at the L.U.M. Jean Monnet University of Bari - Casamassima, in agreement with the John Naisbitt University of Beograd (Serbia) and the South East European University - Macedonia. He is the author of numerous publications, including three books ( $«$ Scritture private e firme elettroniche» - 2004, «Due diligence e responsabilità» -2008 and «Beni di consumo e disciplina delle vendite aggressive» - 2013) and numerous articles, among others, on civil offences, pre-contractual information, forms and contractual evidence, standard contracts, sales, real estate registers, documentary evidence, consumer protection, electronic commerce, sports organizations, ADR. 


\section{Derechos de autor}

Los derechos de autor (para la distribución, comunicación pública, reproducción e inclusión en bases de datos de indexación y repositorios institucionales) de esta publicación (Cuadernos Europeos de Deusto, CED) pertenecen a la editorial Universidad de Deusto. El acceso al contenido digital de cualquier número de Cuadernos Europeos de Deusto es gratuito inmediatamente después de su publicación. Los trabajos podrán leerse, descargarse, copiar y difundir en cualquier medio sin fines comerciales y según lo previsto por la ley; sin la previa autorización de la Editorial (Universidad de Deusto) o el autor. Así mismo, los trabajos editados en CED pueden ser publicados con posterioridad en otros medios o revistas, siempre que el autor indique con claridad y en la primera nota a pie de página que el trabajo se publicó por primera vez en CED, con indicación del número, año, páginas y DOI (si procede). Cualquier otro uso de su contenido en cualquier medio o formato, ahora conocido o desarrollado en el futuro, requiere el permiso previo por escrito del titular de los derechos de autor.

\section{Copyright}

Copyright (for distribution, public communication, reproduction and inclusion in indexation databases and institutional repositories) of this publication (Cuadernos Europeos de Deusto, CED) belongs to the publisher University of Deusto. Access to the digital content of any Issue of Cuadernos Europeos de Deusto is free upon its publication. The content can be read, downloaded, copied, and distributed freely in any medium only for non-commercial purposes and in accordance with any applicable copyright legislation, without prior permission from the copyright holder (University of Deusto) or the author. Thus, the content of CED can be subsequently published in other media or journals, as long as the author clearly indicates in the first footnote that the work was published in CED for the first time, indicating the Issue number, year, pages, and DOI (if applicable). Any other use of its content in any medium or format, now known or developed in the future, requires prior written permission of the copyright holder. 